\title{
Diet, Dental Caries and Other Degenerative Diseases
}

\begin{abstract}
Mankind was introduced to dental caries and degenerative diseases approximately $10,000 \mathrm{BC}$, when the diet changed as a result of moving from a hunter-gatherer to the agriculture life style. The same phenomena occurred when primitive people on primitive diets and basically free of dental caries and degenerative diseases were introduced to the modem diet. Current data generated by the US govemment in the NHANES study, show that dental caries in children precede degenerative diseases later in life. Other studies a re finding some degenerative changes in adolescence. Thus, diet and dental caries should be given greater importance as they can be an indicator of the probability of future degenerative diseases.
\end{abstract}

\section{Introduction}

The paradigms of dentistry have evolved from G.V. Black's notion in the 1890's of viewing dentistry from a single tooth view point (a clean tooth is a healthy tooth); to management of the full mouth, e.g. fluoride applications to reduce the incidence of decay and later to re-mineralization of tooth structure; to caries seen as a disease of the mouth with a "medical model" promoted. Now, caries is seen as part of a group of diet related diseases, e.g. overweight, obesity, cardiovascular, cancer, and more [1-11]. Indeed caries may be the first and easiest sign to note of these impending degenerative diseases [12].

Dental caries rate is an important indicator of lifestyle. If this life style leads to degenerative diseases, the dental caries may be reclassified as part of the degenerative disease(s) such as diabetes, heart disease, cancer. Further, dental caries may be an early indicator of other degenerative diseases, as dental caries usually appears before the other diseases and has a much shorter developmental time, i.e. months vs. years. Thus, diet counseling for dental caries reduction should be more vigorous than just reducing the amount and frequency of sugar and starch intake, and focus on the overall promotion of general health, which would include a diet that will reduce or prolong the onset of other degenerative diseases.

To begin to understand the relationship of dental caries to other degenerative diseases, the history of mankind, dental caries and degenerative diseases to diet will briefly be discussed, plus a series of observations that showed when the modern diet was introduced to primitive people degenerative diseases followed. Finally the state of health related to diet in the US will be shown from data of NHANES studies [13].

\section{Brief History of Mankind and Degenerative Diseases}

Caries is an easily observable finding in human remains that are retrieved from archaeological excavations. These lesions remain indefinitely allowing inference along with other archaeological and ecological data the types of food that a specific population consumed, the type of cooking technology, the relative frequency of consumption and the way food was shared [14].

\section{Journal of}

Oral Biology

\section{George E. White*}

Health Professions Division, College of Dental Medicine, Nova Southeastern University, FL, USA

\section{*Address for Correspondence}

George E. White, Professor, DDS, PhD, DBA, MAGD, FAAPD, FICD, FACD, FACN, Health Professions Division, College of Dental Medicine, Nova Southeastern University, Post Graduate Pediatric Clinic, 819 East 26th Street Fort Lauderdale, Wilton Manors, FL 33305, USA, Tel: 954567- 5650; E-mail: gwhite1@nova.edu

Submission: 25 May 2015

Accepted: 17 June 2015

Published: 20 June 2015

The Neanderthals (230,000-30,000 BP) show the presence of caries, which suggests dietary conditions compatible with the consumption of some cariogenic carbohydrates, despite the huntergatherer lifestyle and the cold climate existing during the Middle Paleolithic [14].

The beginning of the "Neolithic" or New Stone Age period occurred around 10,000 B.C. and is defined by the new way of life based on the production of food from domesticated species. It appears at different times and regions around the world during this time [14]. This was probably necessary to feed a growing population, as hunting and gathering can support one person per 10 square miles, whereas, Neolithic agriculture can support 100 times more $[15,16]$.

Lanfranco and Eggers reviewed many studies on the frequency of caries in prehistoric man and summarized the findings as follows: hunter-gathers had a caries frequency ranging from 0-5.3; fisherman 0.4-10.3 and farmers 2.2-26.9 [14]. While there are disputes among investigators as to the method of gathering data, the trend is clear, as the diet changed, the amount of dental caries increased.

Of great importance for the hunter-gather, they rarely died of coronary artery disease, diabetes mellitus or chronic obstructive pulmonary disease, among other ailments common in societies like ours. They may not have been healthier in absolute terms, but they were absent infection and osteoarthritis and rarely had chronic diseases that we commonly have [17].

Caselitz analyzed the historical evolution of caries in 518 human populations of Europe, Asia and America in a wide timeline from the Paleolithic to the present, confirming that during Paleolithic and Mesolithic periods, the hunter-gatherers had less caries and lesions progressed more slowly [11]. Caries indices have increased gradually from Neolithic times, until they reach the high rates observed at the present. Remarkable caries increments occurred during the second half of the 19th century, when dramatic increases in the intake of sugar and refined carbohydrates between 1830 and $1880[16,18]$.

In most respects, the changes in diet from hunter-gatherer times to agricultural times have been almost all detrimental. With the much heavier reliance on starchy foods that became the staples of the diet, tooth decay, malnutrition, and rates of infectious disease increased dramatically over Paleolithic times, further exacerbated by crowding leading to even higher rates of communicable infections [19]. 
Skeletal remains show that height decreased by four inches from the Late Paleolithic to the early Neolithic period, brought about by poorer nutrition, and perhaps also by increased infectious disease causing growth stress, and possibly by some inbreeding in communities that were isolated. Signs of osteoporosis and anemia, which were almost non-existent in pre-Neolithic times, have been frequently noted in skeletal pathologies observed in the Neolithic peoples of the Middle East. It is known that certain kinds of osteoporosis which have been found in these skeletal remains are caused by anemia, and although the causes have not yet been determined exactly, the primary suspect is reduced levels of iron thought to have been caused by the stress of infectious diseases rather than dietary deficiency, although the latter remains a possibility [20].

The gradual spread of agriculture throughout the Old and New Worlds in the Holocene, and the generally (but not universally) associated traits are an increase in population and in many cases a general decline in health and stature and the appearance of new nutritional disorders [21]. Thus, early in mankind's history the association of diet, dental caries and degenerative diseases is seen

Since 1860 the importation of cane sugar caused impressive improvements in per-capita consumption [22]. In the 1840 decade England, USA and Canada had an approximate consumption of 30 $\mathrm{lb} /$ person. At the end of the century those amounts raised to around $80 \mathrm{lb}$ in England, $60 \mathrm{lb}$ in USA and $50 \mathrm{lbs}$ in Canada [22,23]. Today we are consuming an average of 150-170 lb of sugar per person [24]!

It has shown that consuming 75 to 100 grams of simple sugars (about 20 teaspoons of sugar - the amount found in two-and-a-half average 12 ounce cans of soda) can suppress the immune responses of the body considerably [25].

The change of diet from hunter gatherer to agriculture with grain being introduced into the diet resulted in tooth decay, osteoporosis, and anemia, which are early signs of degeneration. These are the same findings that are noted today in children with ECC (early childhood caries) and S-ECC (severe-early childhood caries) [26-30].

The available data indicates that the modern trends on caries increases start simultaneously with permanent growth intake of sucrose during the last two centuries. The hypotheses of an increase in the susceptibility of resistance diminished by genetic reasons or the installation of a particularly cariogenic flora have not been sufficiently corroborated $[14,28,31,32]$ while dietary changes seem to be the most reasonable answer. In the modern western world and increasingly in other regions of the globe approximately half of consumed calories are from carbohydrates and almost half of it is sucrose [14].

Until recently, several populations living in isolated areas of the world kept their ancestral ways of life (for instance, many African tribes, Inuits, South American Indians, Melanesian, Polynesian) develop progressively destructive caries patterns [14].

It is noted that over a period of thousands of years the diet changed for various reasons and degenerative diseases began. Examples of the same changes seen across the globe in a single life time of a person will be discussed. Price studied primitive and isolated people prior to the introduction of the modern diet [33]. He found that these people were fundamentally without degenerative diseases until the introduction of the modern diet.

\section{Primitive People, Dental Caries and Degenerative Diseases}

In the 1930's Price noticed that there was more decay and deteriorating faces of patients in his Cleveland dental practice [33]. He noticed crowded and misaligned teeth were becoming more prevalent. These children had facial deformities of overbites, narrowed faces, underdevelopment of the nose, lack of well-defined cheekbones and pinched nostrils.

These same children had other systemic effects in that they suffered from frequent infections, allergies, anemia, and asthma, poor -vision, lack of coordination, fatigue and behavioral problems. Many of these same or similar findings are found in the NHANES reports years' later [13].

Instead of studying the disease(s) related to decay, Price decided that if he wanted to know about health, he should go to areas of the world where health existed and dental decay and other degenerative diseases did not exist or were in minimal amounts. He travelled for 10 years making observations and took over 15,000 photographs. He investigated 14 remote areas in the world, including: isolated Swiss villages, remote island of the coast of Scotland, studied traditional Eskimos, Indian tribes in Canada and the Florida Everglades, South sea islanders, Aborigines in Australia, Maoris in New Zealand, Peruvian and Amazonian Indians and tribesman in Africa [33].

His observations found less than $1 \%$ of these people had decay in their permanent teeth. He found that freedom from caries always went hand in hand with freedom from chronic diseases like cancer and heart disease and infectious diseases like tuberculosis, which at the time was a world-wide epidemic [33]. Others have reported the lack of degenerative diseases, particularly cancer in isolated groups [34].

More importantly, these people were healthy with well formed, broad faces and teeth in perfect alignment. Their bodies were wonderful in physical development [33]. The diets of the healthy "primitives" Price studied were all very different (in other words it was not so much what they ate that contributed to their health as what they did not eat).

Similar findings have been found recently in several populations living in isolated areas of the world where they kept their ancestral ways of life (e.g. many African tribes, Inuits, South American Indians, Melanesian, Polynesian, under conditions of perfect adaptation to their environments and diets [35-37].

Bacteriological analyses of their dental plaques, although not extensive, show cariogenic species, but those individuals are still developing few or no caries. Otherwise, when those populations were acculturated or simply replaced the traditional diet for an "occidental refined diet", they started to develop progressively destructive caries patterns [14].

Modern nutrition researchers are showing renewed interest in the foods of our ancestors, but myths about primitive diets abound. The first is easily dismissed-that traditional diets were largely vegetarian. Anthropological data confirm what Price found, namely that throughout the globe, all societies show a preference for animal foods and fats [20]. Modern scientific literature does not support the claims made for vegetarian diets [38]. 
Arctic explorers reported great longevity among the Eskimo [35] Australian Aborigine communities were noted for containing a size able number of old people, who lived together as a separate group and for whom were reserved special foods that were easy to gather and hunt [39]. The diets of traditional groups noted for longevity are rich in animal fats: The people of Hunza consume large quantities of fermented goat milk products, and goats milk is higher in fat, and contains more saturated fat, than cow's milk; the inhabitants of Vilcabamba in Equator consume fatty pork and whole milk products; and the long-lived inhabitants of Soviet Georgia also eat liberally of pork and whole milk yoghurt and cheeses. In fact, a Soviet study found that longevity was greatest in rural communities where people ate the most fatty meat, compared to town dwellers who ate more carbohydrates $[40,41]$.

Carbohydrates, in the form of whole grains and related seed foods, are not absent in healthy traditional diets, even in the diets of hunter-gatherers. Price found that millet and corn were consumed throughout Africa; quinoa and amaranth in South America. American Indians consumed wild rice, corn and beans; Australian Aborigines gathered a species of wild millet and consumed a large variety of legumes. One school of thought claims that grains and pulses should be avoided, arguing that they were absent from the Paleolithic diet and citing the obvious association of grains with celiac disease and studies linking grain consumption with heart disease $[21,41]$.

What researchers often overlook is the fact that seed foods, e.g. grains, legumes and nuts, are prepared with great care in traditional societies, by sprouting, roasting, soaking, fermenting and sour leavening [42]. These processes neutralize substances in whole grains and other seed foods that block mineral absorption, inhibit protein digestion and irritate the lining of the digestive tract. Such processes also increase nutrient content and render seed foods more digestible.

Another food revolution that had an equally great impact on oral health occurred with the introduction of agriculture. This innovation in both technical and food, agriculture modified the diet of ancient populations by providing new foods that were rich in carbohydrates and by introducing new cooking methods, i.e. food was not often boiled instead of being roasted. These two factors alone contributed to an increased rate of dental caries, but at the same time reduced the abrasion of occlusal surfaces [33,34].

\section{National Health Findings}

Degenerative Diseases found in the National Health and Nutrition Examination Survey (NHANES) [34] give the data to support this notion of a spectrum of diet related degenerative diseases.

The NHANES [13] project found that the following statistics related to diet consumption:

${ }^{\star}$ More than 1 in 3 children and adolescents aged 6 to 19 are considered to be overweight.

${ }^{*}$ More than 2 in 3 adults are considered to be overweight or obese.

${ }^{\star}$ About 1 in 3 children and adolescents aged 6 to 19 are considered to be obese. Thus, overweight and obesity is seen to increase with age.

${ }^{\star}$ More than 1 in 3 adults are considered to be obese.

The health risks of overweight and obesity are: [39] type 2 diabetes, heart disease, high blood pressure, non-alcoholic fatty liver disease, osteoarthritis, cancers, such as, breast, colon, endometrial kidney and stroke.

It is generally thought that the above degenerative diseases are found only in adults, but autopsy studies have shown that atherosclerosis begins in adolescence in otherwise seemingly healthy individuals [43], and imaging techniques have shown that atherosclerosis develops earlier and is more prevalent in children with diabetes than in age-matched healthy controls. Cardiovascular disease has now overtaken diabetic nephropathy as the leading cause of premature mortality in young adults with diabetes. The majority of children and adolescents with diabetes have suboptimal blood glucose control and this contributes to accelerated arterial disease in this age group [44].

Recent findings from NHANES [13] show that there is lack of evidence that the recommended diet is useful in preventing degenerative diseases and that the population has degenerative diseases.

There is moderate evidence for the relationship between adherence to dietary guidelines/recommendations or specific dietary patterns, assessed using an index or score, and measures of body weight or obesity that, in adults, increased adherence to dietary patterns scoring high in fruits, vegetables, whole grains, legumes, unsaturated oils, and fish; low in total meat, saturated fat, cholesterol, sugar-sweetened foods and drinks, and sodium; and moderate in dairy products and alcohol is associated with more favorable outcomes related to body weight or risk of obesity, with some reports of variation based on gender, race, or body weight status.

There is moderate evidence that adherence to a dietary pattern that emphasizes vegetables, fruits, and whole grains is associated with modest benefits in preventing weight gain or promoting weight loss in adults using methods other than index/score, cluster or factor, or reduced rank regression analyses, and body weight status.

The evidence of a "good modern recommended diet" is inconclusive for preventing degenerative diseases. There does not appear to be a diet from NHANES that would prevent or reduce degenerative diseases. Could this possibly be because sugar and all its forms are not isolated in the analyses? In other words, it is not the fact that one eats a healthy diet that promotes health, it is the sugar that promotes disease.

Since 1996, a consortium formed by CDC and the National Institute of Dental and Craniofacial Research (NIDCR) has developed and implemented a plan to use the National Health and Nutrition Examination Survey (NHANES) to obtain epidemiologic estimates of dental conditions and preventive efforts. They found that: [13]

${ }^{*} 41 \%$ of children aged 2 to 11 had dental caries in primary teeth

${ }^{\star} 42 \%$ of children aged 2 to 11 had dental caries in permanent teeth

${ }^{\star} 90 \%$ of adults had dental caries [13].

It appears that dental caries is preceding the development of the other degenerative diseases. It should not be surprising as they are all related to nutrition. Childhood caries could be an important marker to make changes in the diet of the individual so as to ward off further degenerative diseases or at least delay the onset. 
Caries affects nutrition dental health and general health. Children with early childhood caries (ECC) were significantly more likely to weigh less than $80 \%$ of their ideal weight, thereby satisfying one of the diagnostic criteria for failure to thrive [26].

Similar findings were more recently found that suggests that higher levels of untreated caries are associated with poorer growth in school children $[27,28]$.

Young children with ECC or S-ECC (severe-childhood caries) were very likely to be found with systemic effects showing how this spectrum of degeneration begins. They were likely:

${ }^{*}$ Weigh less than $80 \%$ of their ideal weight [26]

${ }^{\star}$ Low in vitamin D [29]

${ }^{\star}$ Low in Calcium [29]

${ }^{\star}$ Low in albumin concentrations [29]

${ }^{\star}$ Low ferritin status [29]

${ }^{\star}$ Greater odds for iron deficiency anemia [30]

Children with higher levels of untreated caries:

*poorer growth $[27,28]$

${ }^{\star}$ Elevated BMI percentiles increased risk to general health [37]

Malnourished children have been shown to have decrease physical activity and endurance, poorer cognitive function and school performance. Multiple single micronutrient deficiencies, including vitamin B12, thiamin, niacin, zinc and iron, have been associated with poorer cognitive performance. Behavioral problems, including attention deficits, have also been associated with food insufficiency and malnutrition [45].

Conversely a healthy eating pattern geared for promotion of optimal child development and prevention of chronic disease in later life, may also reduce the risk of early childhood caries [46].

\section{Diet, Dental Caries and Diseases}

The available data indicates that the modern trends on caries increases start simultaneously with permanent growth intake of sucrose during the last two centuries. In the modern western world and increasingly in other regions of the globe, approximately half of consumed calories are from carbohydrates and almost half of it is sucrose [14].

WHO states that Non-Communicable Diseases (NCDs) are the leading causes of death and were responsible for 38 million (68\%) of the world's deaths in 2012. Modifiable risk factors such as poor diet and physical inactivity are some of the most common causes of NCDs; they are also risk factors for obesity, an independent risk factor for many NCDs, which is also rapidly increasing globally. A high level of free sugars intake is of concern, because of its association with poor dietary quality, obesity and risk of NCDs [47].

Three national population studies were identified that enabled comparison of dental caries levels when annual per capita free sugars intake was less the $10 \mathrm{~kg} /$ person/year (about $5 \%$ of total energy intake, compared with more than $10 \mathrm{~kg} /$ person/year but below levels of dental caries development were observed when per capita free sugars intake was less than $10 \mathrm{~kg} /$ person/year. Across all studies, a log-linear dose-response relationship was also observed at free sugars intakes well below $10 \mathrm{~kg} /$ person/year (i.e. <5\% of total energy intake) [47].

Evidence suggests that risk for early childhood caries (ECCs), the most common chronic infectious disease in childhood, is increased by specific eating behaviors, [48] which the same or similar to diets related to systemic diseases like obesity, atherosclerosis, and cardiovascular diseases in children. However, Qadri et al. found that although iso-BMI (Body Mass Index) was associated with dental caries prevalence and severity, the association between caries increment and iso-BMI did not reach a statistical significance [49]. Overweight/obese children, however, acquired more additional carious lesions during the follow-up period than children with lownormal weight. The findings [48] namely obesity, atherosclerosis and cardiovascular diseases, may occur by several mechanisms, one way is the over consumption of sugar sweetened beverages.

A cross sectional study found after control for many factors that children with the highest SSB intake (sugar sweetened beverages) were 2.0 to 4.6 times more likely to have severe ECCs compared with those with the lowest SBB intake [50]. High SBB intake can be related to over-weight, obesity, cardiovascular disease and cancer. If the liver is full of glycogen when fructose is ingested, the fructose is converted to liver fat [51]. If this becomes a chronic condition, then fatty liver disease can result [52,53]. Fatty liver is a major risk factor for heart disease [52]. The liver metabolizes fructose to uric acid, which at low levels is a protective factor in the blood stream. However, at high levels, such as those now found, it can result in joint symptoms like gout and kidney disease [51-56]. Uric acid impairs the effectiveness of insulin, [54-57] which can lead to insulin-resistance, putting additional stress on the cardiovascular system [43].

\section{Summary}

1. Dental caries appears to be an early indicator of systemic degenerative diseases:

(a) Dental caries appear prior to other clinical degenerative disease(s),

(b) All these diseases are nutritionally related, especially to sugar and starches,

(c) Historically these diseases appear together.

2. Historically dental caries and other degenerative diseases began to influence society with the introduction of grains to the diet, when the population shifted from hunter/gatherer to agriculture based diet.

3. Primitive peoples in the past were seen to be free of dental caries and degenerative diseases until the introduction of the modern diet.

4. Children with highest consumption of SBB had early childhood caries. SBB is known to be related to overweight, obesity, kidney disease, fatty liver, cardiovascular disease and cancer.

\section{References}

1. White GE (2015) CAMBRA: Is there more to this? J Oral Biol 2: 1-5.

2. Yao $Y$, Ren $X$, Song $X$, He L, Jin $Y$, et al. (2014) The relationship between dental caries and obesity among primary school children aged 5 to 14 years. Nutr Hosp 30: 60-65. 
3. Panwar NK, Mohan A, Arora R, Gupta A, Marya CM, et al. (2014) Study on relationship between the nutritional status and dental caries in 8-12 year old children of Udaipur City, India. Kathmandu Univ Med J (KUMJ) 12: 26-31.

4. Yang F, Zhang Y, Yuan X, Yu J, Chen S, et al. (2015) Caries experience and its association with weight status among 8-year-old children in Quindao, China. J Int Soc Prev Community Dent 5: 52-58.

5. Costacurta M, DiRenzo L, Sicuro L, Gratteri S, De Lorenzo A, et al. (2014) Dental caries and childhood obesity: analysis of food intakes, lifestyle. Eur J Paediatr Dent 15: 343-348.

6. Vartanian LR, Schwartz MB, Brownell KD (2007) Effects of soft drink consumption on nutrition and health: a systematic review and meta-analysis. Am J Public Health 97: 667-675.

7. Hamel C, Stevens A, Singh K, Ansari MT, Myers E, et al. (2014) Do sugar-sweetened beverages cause adverse health outcomes in adults? A systematic review protocol. Syst Rev 3: 108

8. Pan L, Li R, Park S, Galuska DA, Sherry B, et al. (2014) A longitudinal analysis of sugar-sweetened beverage intake in infancy and obesity at 6 years. Pediatrics 134: S29-S35.

9. Cheungpasitporn W, Thongprayoon C, Corragain OA, Edmonds PJ, Kittanamongkolchai W, et al. (2014) Associations of sugar-sweetened and artificially sweetened soda with chronic kidney disease: a systematic review and meta-analysis 19: 791-797.

10. Kumar GS, Pan L, Park S, Lee-Kwan SH, Onufrak S, et al. (2014) Sugarsweetened beverage consumption among adults - 18 states. (MMWR)Morib Mortal Wkly Rep 63: 686-690.

11. Hu FB (2013) Resolved: there is sufficient scientific evidence that decreasing sugar-sweetened beverage consumption will reduce the prevalence of obesity and obesity-related diseases. Obes Rev 14: 606-619.

12. White GE (2014) Oral health: A window into general health. J Oral Biology 1: $1-5$

13. http://www.cdc.gov/

14. Lanfranco LP, Eggers S (2012) Caries through time: An anthropological overview. Contemporay Approach to Dental Caries.

15. Molnar S, Molnar I (1995) Observations of dental diseases among prehistoric populations of Hungary. Am J Phys Anthropol 67: 51-63.

16. Caselitz P. Caries ancient plague of humankind. 1998 In: Dental Anthropology Fundamentals, Limits and Prospects. Alt, KW Rosing, FW, Teschler-Nicola M (eds.), Springer, Wien, New York, pp 203-226.

17. Eaton SB, Monner M (1985) Paleolithic nutrition: A consideration of its nature and current implications. N Engl J Med 312: 283-289.

18. Moore WJ, Corbett ME (1975) Distribution of dental caries in ancient British populations III. The 17th century. Caries Res 9: 163-175.

19. Richards MP (2002) A brief review of the archeological evidence for Palaeolithic and Neolithic subsistence. Eur J Clin Nutr 56: 1270-1278.

20. Moore WJ (1993) Dental caries in Britain. In: Food, Diet and Economic Change Past and Present. Geissler C. Oddy DJ (eds), Leicester University Press, Leicester, pp 50-61.

21. Blake M, Clark JE, Chisholm B, Mudar K (1992) Non-agricultural staples and agricultural supplements: Early Formative subsistence in the Soconusco region, Mexico. In: Transitions to Agriculture in Prehistory. ed. AB Gebauer \& TD Price, 1992, Madison, Prehistory Press, pp 133-151.

22. Cohen MN, Armelagos GJ (1984) Paleopathology and the origins of agriculture london, Academic Press.

23. Saunders S, De Vito C, Katzenberg A (1997) Dental caries in nineteenth century upper Canada. Am J Phys Anthropol 104: 71-87.

24. Boyce G (1972) Hutt of hastings mika and mika, belleville, Ontario.

25. USDA (2010) Profiling Food Consumption in America. United States Department of Agriculture. Sowers, Robert.
26. Sanchez A, Reeser JL, Lau HS, Yahiku PY, Willard RE, et al. (1973) Role of sugars in human neutrophilic phagocytosis. Am J Clin Nutr 26: 1180-1184.

27. Smith, Russell (1998) Vegetarian Studies. Health and Healing Wisdom, Price-Pottenger Nutrition Foundation, Winter 30: 574-776.

28. Kabara JJ (1989) The Pharmacological Effects of Lipids, Kabara JJ ed, The American Oil Chemists Society, p 366

29. Garg M L (1998) The FASEB Journal 1988, 2:4:A852; Oliart Ros, R M, et al, Meeting Abstracts, AOCS Proceedings, Chicago, IL, p 7.

30. Lawson, LD, Kummerow FA (1979) $\beta$-Oxidation of the coenzyme a esters of vaccenic, elaidic and petroselaidic acids by rat heart mitochondria. Lipids 14 : 501-503.

31. de Soet JJ, Lane ML (2008) Genetics and caries. Ned Tijdschr Tandheelkd 115: 78-82.

32. Hassell TM, Harris El (1995) Genetic influences in caries and periodontal diseases. Crit Rev Oral Biol Med 6: 319-42.

33. Price WA (1945) Nutrition and physical degeneration, Price-Pottenger Nutrition Foundation, San Diego, CA.

34. Richards MP (2002) A brief review of the archeological evidence for Paleolithic and Neolithic subsistence. Eur J Clin Nutr 56: 1270-1278.

35. Mayhall JT (1977) The effect of culture change upon the Eskimo dentition. Artic Anthropol 7: 117-121.

36. Shuler CF (2001) Inherited risks for susceptibility to dental caries. J Dent Educ 65: 1038-1045.

37. Donnelly CJ, Thomson LA, Stiles HM, Brewer C, Neel JV, et al. (1997) Plaque, caries, periodontal diseases and accumulation among Yanomamö Indians, Venezuela. Community Dent Oral Epidemiol 5: 30-39.

38. Imamura K (1996) The transition to agriculture in Japanese prehistory. In: The Origins of Agriculture and Pastoralism in Eurasia, London: UCL Press, pp 442-464.

39. Bellwood P (1996) The origins and spread of agriculture in the Indo-Pacific region: gradualism and diffusion or revolution and colonization? In: The Origins of Agriculture and Pastoralism in Eurasia, London: UCL Press pp 465-498.

40. Flannery KV (1973) The origins of agriculture. An Rev Anthropol 2: 271-310.

41. Walker PL, Hewlett BS (1990) Dental health, diet and social status among central African foragers and farmers. Am Anthropol 92: 383-398.

42. Goldsmith Z (1998) Cancer: A disease of industrialization. Ecologist 28: 9399

43. Berenson GS, Srinivasan SR, Bao W, Newman WP 3rd, Tracy RE, et al. (1998) Association between multiple cardiovascular risk factors and atherosclerosis in children and young adults. The Bogalusa Heart Study. N Engl J Med 338: 1650-1656

44. Crawford GW (1992) The transitions to agriculture in Japan. In: Transitions to Agriculture in Prehistory. ed. Gebauer AB, Price TD, Madison: Prehistory Press, pp 117-132.

45. Gagne G (1993) Mouth diseases in prehistoric agricultural population of northeastern North America. J Can Dent Assoc 59: 686-692.

46. Morell SF (1995) "Vitamin A Vagary," PPNF Health Journal, Price-Pottenger Health Journal, 619: 574-7763.

47. Nunn ME, Braunstein NS, Kroll Kaye EA, Dietrich T, Garcia RI, et al. (2009) Healthy eating index is a predictor of early childhood caries. J Dent Res 88 : 361-366.

48. WHO (2015) Sugar intake for adults and children. Guideline. World Health Organisation.

49. Qadri G, Alkilzy M, Feng YS, Splieth C (2015) Overweight and dental caries: the association among German children. Int J Paediatr Dent 25: 174-182.

50. Mobley C, Marshall TA, Milgrom P, Coldwell SE (2009) The contribution of 
Citation: White GE. Diet, Dental Caries and Other Degenerative Diseases J Oral Bio. 2015;2(2): 6.

ISSN: $2377-987 X$

dietary factors to dental caries and disparities in caries. Acad Pediatr 9: 410414

51. Evans EW, Hayes C, Palmer CA, Bermudez OL, Cohen SA, et al. (2013) Dietary intake and severe early childhood caries in low-income, young children. J Acad Nutr Diet 113: 1057-1061.

52. Khitan Z, Kim DH (2013) Fructose: A key factor in the development of metabolic syndrome and hypertension. J Nutr Metab 2013: 682673.

53. Lustig RH (2010) Fructose: metabolic, hedonic and societal parallels with ethanol. J Am Diet Assoc 110: 1307-1321.
54. Johnsom RJ, Lanaspa-Garcia MA, Dreskin S (2011) Methods for fructanase and fructokinase inhibition, US20130195886 A1.

55. Stanhope KL, Havel PJ (2008) Fructose consumption: potential mechanisms for its effects to increase visceral adiposity and induce dyslipidemia and insulin resistance. Curr Opin Lipidol 19: 16-24.

56. Seeds B (2014) The fructose disease: The biggest medical paradigm shift of the 21 st century. Third edition.

57. Feig DI, Kang DH, Johnson RJ (2008) Uric acid and cardiovascular risk. N Engl J Med 359: 1811-1821. 